\title{
Foreign Body Aspiration from Tracheostomy Inlet
}

\author{
Polat Durukan', Ali Duman', Seda Özkan', Ömer Salt', Leyla Hasdıraz², Fahri Oğuzkaya² \\ 'Department of Emergency Medicine, Erciyes University Faculty of Medicine, Kayseri, Turkey \\ ${ }^{2}$ Department of Thoracic Surgery, Erciyes University Faculty of Medicine, Kayseri, Turkey
}

\begin{abstract}
Tracheobronchial foreign body aspiration is an important life-threatening clinical condition that requires emergency intervention. Compared with children, foreign body aspiration is rare in adults and sometimes could be fatal. The most common symptom is severe coughing that appears after choking. Foreign body aspiration should be considered in the diagnosis of patients with wheezing, chronic cough, voice alteration, hoarseness, or recurrent pulmonary infections. A 78-year-old male patient with tracheostomy due to laryngeal cancer was admitted to the emergency department on account of aspiration of tweezers after coughing when he was cleaning the tracheostomy cannula. The patient complained of shortness of breath and coughing. Physical examination revealed decreased breath sounds on the right side of the lung, and he had dyspnea and central cyanosis. There was a foreign body extending from the carina to the right main bronchus on the posteroanterior radiograph of the lung. In the operating room, rigid bronchoscopy was performed from the tracheostomy stoma and the foreign body was removed using forceps. This case shows that patients with tracheostomy and their relatives must be well educated in the care of stoma. Rigid bronchoscopy by an experienced specialist for foreign body aspiration is a safe and effective method for diagnosis and treatment.

(Eurasian J Emerg Med 2015; 14: 142-4)
\end{abstract}

Keywords: Tracheostomy, foreign body, emergency medicine

\section{Introduction}

Tracheobronchial foreign body aspiration is an important life-threatening clinical condition that requires emergency intervention. Compared with children, foreign body aspiration is rare in adults and sometimes could be fatal (1). The most common symptom is severe coughing that appears after choking. Foreign body aspiration should be considered in the diagnosis of patients with wheezing, chronic cough, voice alteration, hoarseness, or recurrent pulmonary infections. When foreign bodies are stuck in the bronchi for a long time, various complications such as atelectasis, chronic lung infection, abscess, and bronchiectasis may develop (2).

Safe and quick removal of the foreign body is very important for relief of symptoms and to avoid serious complications. In order to remove the foreign body in children, usually rigid bronchoscopy is used; in adults, rigid and fiberoptic bronchoscopy can be used (3). In parallel with the developments in anesthesia and bronchoscopy, the morbidity and mortality rates associated with foreign body removal by experienced hands have decreased below $1 \%$ (4).

\section{Case Presentation}

A 78-year-old male patient with tracheostomy due to laryngeal cancer was admitted to the emergency department on account of aspiration of tweezers after coughing when he was cleaning the tracheostomy cannula (Figure 1). The patient complained of shortness of breath and coughing. Physical examination revealed decreased breath sounds on the right side of the lung, and he had dyspnea and central cyanosis. Chest radiography showed a radiopaque foreign body extending from the carina to the right main bronchus (Figure 2), and thoracic surgery was indicated. Rigid bronchoscopy was performed after application of aerosol lidocaine into the tracheostomy stoma in the operating room by the chest surgeon. Foreign body with a bright reflection on the carinae was observed on bronchoscopy. The foreign body was removed using forceps (Figure 3). After the procedure, control chest radiography was performed. The patient was advised about maintenance of the tracheostomy cannula and was subsequently discharged. The patient provided informed consent to publish this case report.

Correspondence to: Polat Durukan e-mail: polatdurukan@gmail.com 


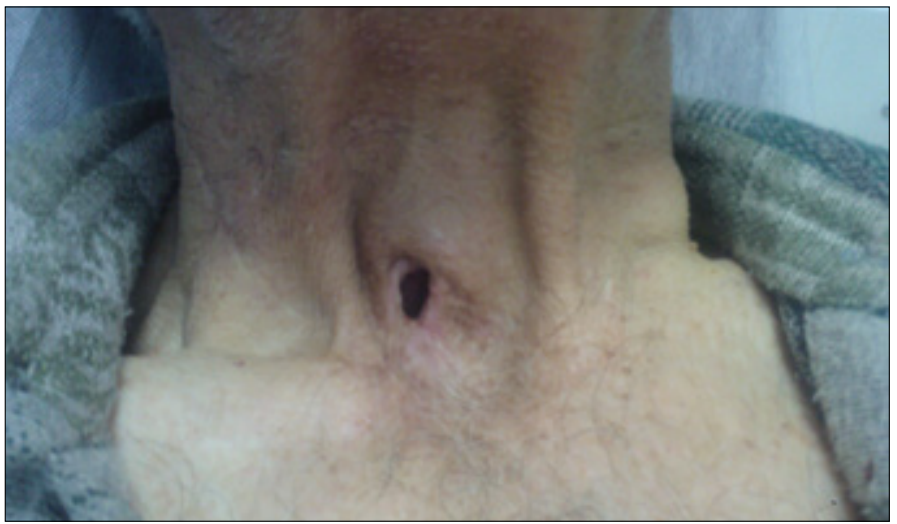

Figure 1. Photograph of the tracheostomy inlet of the patient

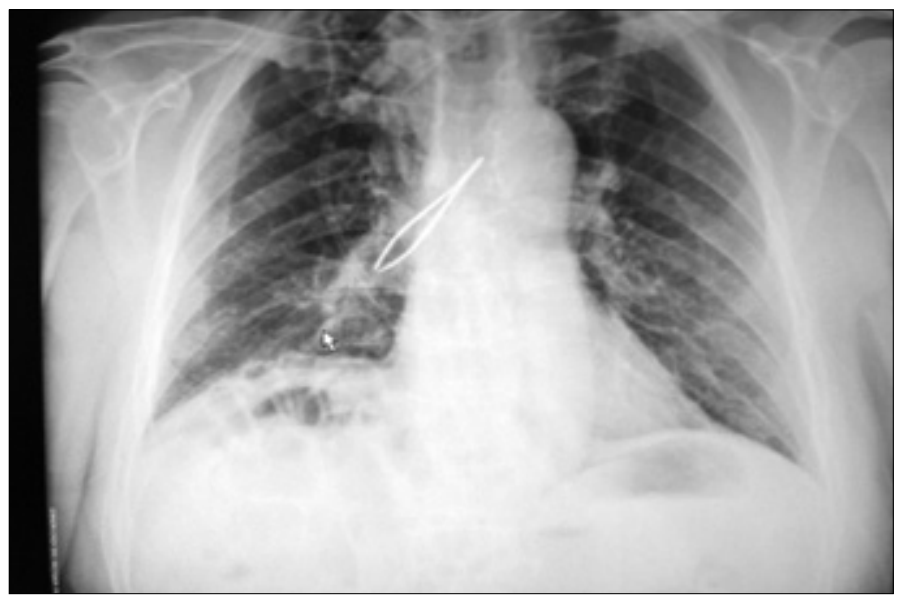

Figure 2. A posteroanterior chest radiograph shows the foreign body

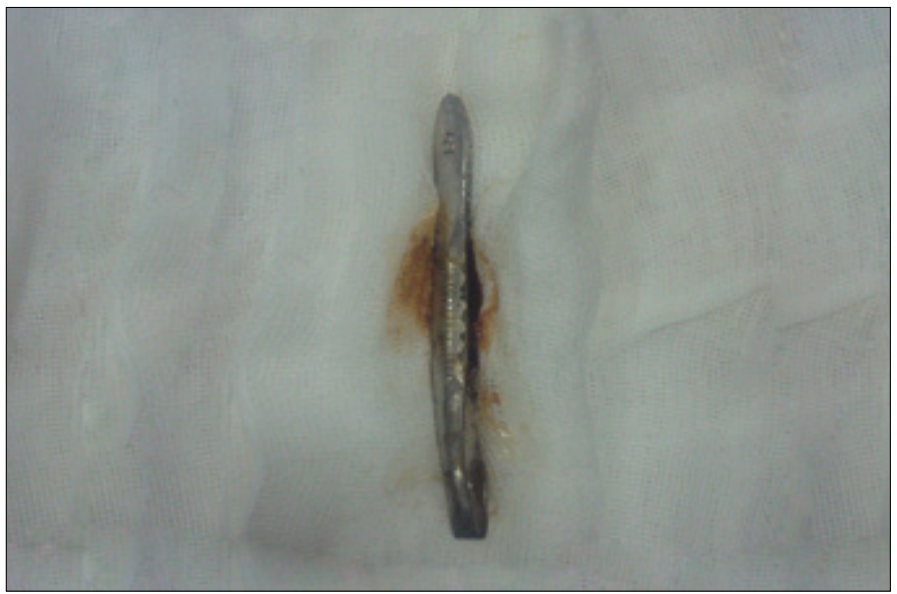

Figure 3. Photograph of the foreign body

\section{Discussion}

Tracheobronchial foreign body aspiration is an important life-threatening clinical condition that requires emergency intervention. Foreign body aspirations are rare in adults compared with children and can sometimes be fatal (1). Foreign body aspiration in older adults usually develops due to some underlying disease. Alcohol, sedative and hypnotic drug use, senility, seizures, general anesthesia, intoxication, traumatic intubation, trauma, loss of consciousness, mental retardation, denture processing, and primary neurological diseases are some factors that predispose an individual to foreign body aspiration. In addition to these facilitative factors, situations that impair airway protective mechanisms, such as tracheostomy, can also result in foreign body aspiration (5).

Stoma results in an increased risk of lower airway foreign body aspiration with obtaining of the foreign body to direct and easily accessible. The protective mechanism of the larynx sphincter is circumvented. The negative intrapleural pressure gradient increases in case of deep inspiration or coughing attacks and creates a vacuum effect around the stoma, increasing the risk of aspiration of more objects. It can result in the aspiration of tools that were used in cleaning the respiratory secretions and stoma by the patients $(6,7)$.

In a previous study, Uzaslan et al. (6) used a fiberoptic bronchoscope to remove a wooden stick that was used to clean respiratory secretions by the patient. In the present case, rigid bronchoscopy was used to remove the tweezers that were aspirated after a coughing attack during the cleaning of stoma.

The case is very important in the diagnosis of tracheobronchial foreign body aspiration. Following foreign body aspiration, the cough is initially spasmodic, dry, and irritative; after the settling of the bronchial foreign body, it loses its intensity and the property (8). Similarly, in the present case, the patient had a history of aspiration and severe attack of coughing.

There is a consensus that the anatomical structure of the right main bronchus and branches of the bronchial tree make it more susceptible to foreign body aspiration (9). In this case, the foreign body extended into the right main bronchus across the carina.

Radiological investigations should be performed in all patients with suspected foreign body aspiration. If the aspirated foreign body is radiopaque, it can be seen easily on a posteroanterior chest radiograph. However, to define the exact location and size of the foreign body, lateral and oblique chest X-rays must also be performed (10). In the present case, the foreign body and its location were determined on the chest X-ray.

Bronchoscopy should be indicated in all patients with a suspected or certain history of foreign body aspiration even in the absence of clinical or radiological symptoms. The preferred method for the removal of a foreign body is rigid bronchoscopy. This method allows the airway to be protected and it becomes easier to remove foreign bodies due to the large internal diameter (11). Execution of the procedure in the operating room by an experienced surgeon and anesthesia team will reduce the associated complications (12). In the present case, the foreign body was removed by rigid bronchoscopy with the help of an experienced surgeon in the operating room.

\section{Conclusion}

The case presented here showed that patients with tracheostomy and their relatives need better training on the maintenance of stoma. Rigid bronchoscopy performed by experienced experts is reliable and effective for the diagnosis and treatment of foreign body aspiration.

Informed Consent: Written informed consent was obtained from patient who participated in this case.

Peer-review: Externally peer-reviewed. 
Conflict of Interest: No conflict of interest was declared by the authors.

Financial Disclosure: The authors declared that this study has received no financial support.

\section{References}

1. Aytac A, Yurdakul Y, Ikizler C, Olga R, Saylam A. Inhalation of foreign bodies in children. Report of 500 cases. J Thorac Cardiovasc Surg 1977; 74: 145-51.

2. Hollinger LD. Foreign bodies in the larynx, trachea, and bronchi. In: Behrman RE, Kliegman RM, Jenson HB (eds). Nelson Textbook of Pediatrics, 17th ed. Philadelphia:WBSaunders, 2004: 1410-1.

3. Rafanan AL, Mehta AC. Adult airway foreign body removal. What's new? Clin Chest Med 2001; 22: 319-30. [CrossRef]

4. Pasaoglu I, Dogan R, Demircin M, Hatipoglu A, Bozer AY. Bronchoscopic removal of foreign bodies in children: retrospective analysis of 822 cases. Thorac Cardiovasc Surg 1991; 39: 95-8. [CrossRef]

5. Çelik P, Yorgancıoğlu A, Çelik O. Laringotrakeobronşial yabancı cisim aspirasyonu. KBB Klinikleri 2000; 2: 50-6.
6. Uzaslan E, Ursavaş A, Ediger D, Karadağ M. An unusual way of tracheal stoma cleaning could end up with foreign body aspiration in a laryngectomized patient. Tuberk Toraks 2005; 53: 61-4.

7. Erpek MG, Yorgancıoğlu A, Çelik P. Yabancı cisimler. ÇelikO (editörler). Kulak Burun Boğaz ve Baş Boyun Cerrahisi. İstanbul: Turgut Yayıncılık, 2002: 985-95.

8. Erikci V, Karacay S, Arikan A. Foreign body aspiration: a four-years experience. Ulus Travma Derg 2003; 9: 45-9.

9. Carluccio F, Romeo R. Inhalation of foreign bodies: epidemiological data and clinical considerations in the light of statistical review of 92 cases. Acta Otorhinolaryngol Italy 1997; 17: 45-51.

10. Beflirli K, Demirkaya A. Trakeobronfliyal yabancı cisim aspirasyonu. Solunum 2003; 5: 316-9.

11. Ludemann J P, Hughes CA, Holinger LD. Management of foreign bodies of the airway. In Shields TW (ed). General thoracic surgery. Philadelphia. Lippincott Williams \& Wilkins; 2000; 853-62.

12. Latifi X, Mustafa A, Hysenaj Q. Rigid tracheobronchoscopy in the management of airway foreign bodies:10 years experience in kosovo. Int $\mathrm{J}$ Pediatr Otorhinolaryngol 2006; 70: 2055-9. [CrossRef] 